\title{
DIRIGENTES E DOMINANTES: CONSIDERAÇÕES SOBRE OS INTEGRANTES DO CONSELHO DE ADMINISTRAÇÃO (CAd) DA COMPANHIA DE SANEAMENTO DO PARANÁ (SANEPAR) ENTRE 1998 E 2002
}

\author{
Marcus Roberto de Oliveira ${ }^{1}$
}

\begin{abstract}
Resumo: A mobilização de inúmeros agentes sociais torna evidente a existência (e a operação) de campos sociais nos em conjunturas que envolvem o planejamento, a implantação e a execução de serviços de água e esgoto, ao movimentar significativos capitais. Numa diversidade de agentes sociais, habitus e interesses, operam e entrelaçam-se uma significativa quantidade de campos sociais; como por exemplo, os campos político, empresarial, profissional, jurídico entre outros. Assim, nos contextos em que os serviços de água e esgoto são planejados, implantados executados e administrados, os campos sociais vigentes podem ser compreendidos enquanto subcampos componentes de um campo num sentido amplo, um campo social Água e Esgoto (AE). Delimitando o caso paranaense, no intuito de compreender as dinâmicas dos agentes e campos sociais que contemplam aquilo que denominamos de campo social AE, o presente texto buscará uma reflexão acerca das formações profissionais e das trajetórias sociais dos integrantes do Conselho de Administração (CAd) da Companhia de Saneamento do Paraná (SANEPAR) entre 1998 e 2002. Nesse intervalo, é possível identificar que os conselheiros administrativos da SANEPAR orientaram suas decisões junto a uma abertura dos ofícios de água e esgoto para o setor privado, juntamente com uma atenção sistemática às ações da empresa no mercado financeiro.
\end{abstract}

Palavras-chave: Capitais. Campos sociais. Agentes sociais. SANEPAR.

\section{Leaders and dominants: considerations on the members of the Board of Directors (CAd) of the Companhia de Saneamento do Paraná (SANEPAR) between 1998 and 2002}

\begin{abstract}
The mobilization of many social agents makes evident the existence (and operation) of social fields in conjunctures that involve the planning, implementation and execution of water and sewage services, when moving significant capitals. In a diversity of social agents, habitus, and interests, a significant number of social fields operate and intertwine; Such as the political, business, professional, legal, among others. Thus, in the contexts in which water and sewage services are planned, implemented, and managed, existing social fields can be understood as component subfields of a field in a broad sense, a Water and Sewage (EA) social field. Delimiting the case of Paraná, in order to understand the dynamics of agents and social fields that contemplate what we call the social field AE, this text will seek a reflection on the professional backgrounds and social trajectories of the members of the Board of Directors (CAd) of the Sanitation Company of Paraná (SANEPAR) between 1998 and 2002. Within this interval, it is possible to identify that SANEPAR's administrative councilors guided their decisions along with an opening of water and sewage services to the private sector, along with a systematic attention to actions Of the company in the financial market.
\end{abstract}

Keywords: Capitals. Social fields. Social agents. SANEPAR.

- Enviado em 15/07/2017

- Aprovado em 28/07/2017

\footnotetext{
${ }^{1}$ Bacharel em Ciências Sociais, mestre em Sociologia Política e doutorando em Sociologia pela Universidade Federal do Paraná (UFPR). E-mail: $\underline{\text { mr_olivei@yahoo.com.br }}$

Uma versão preliminar desse texto foi apresentada no $18^{\circ}$ Congresso Brasileiro de Sociologia. Que Sociologia fazemos? Interfaces com contextos locais, nacionais e globais realizado de 26 a 29 de julho de 2017 no Centro de Convenções Ulysses Guimarães, Brasília/DF.
} 


\section{Introdução}

O abastecimento de água tratada e o esgotamento sanitário demandam uma série de elementos na efetivação de suas respectivas infraestruturas. Nesse ponto, conhecimento técnico, materiais e equipamentos, linhas de financiamento, sensibilizações ambientais entre outras questões (que variam conforme contextos e circunstâncias vigentes) são objetos importantes aos referidos ofícios e conectam numa diversidade de situações que expressam consensos, conflitos, interesses e poder; assim contemplando a vigência de campos sociais.

Mas o que é um "campo social”? Um campo social é um espaço teórico, um microcosmo com regras próprias e relativamente autônomas, sendo tanto um "campo de forças", uma composição que compele os indivíduos, instituições e grupos nele enredados, quanto um "campo de lutas", em que tais agentes sociais obram conforme suas posições junto às relações de forças. Nessa dinâmica, ao mesmo tempo em que estão submetidos às normas do campo social correspondente, os agentes sociais (indivíduo, instituição ou grupo) operam no sentido de conservar ou transformar a estrutura do campo (BOURDIEU, 1996).

Assim, a mobilização de inúmeros agentes sociais torna evidente a existência (e a operação) de campos sociais nos em conjunturas que envolvem o planejamento, a implantação e a execução de serviços de água e esgoto, ao movimentar significativos capitais. Os capitais são os recursos mobilizadores que proporcionam hierarquia à estrutura de um campo social (MATOS, 2009). Podem ser classificados como: "[...] econômico, que compreende a riqueza material, o dinheiro, as ações etc. (bens, patrimônios, trabalho)"; “[...] cultural, que compreende o conhecimento, as habilidades, as informações, etc.”; “[...] social, correspondente ao conjunto de acessos sociais, que compreende o relacionamento e a rede de contatos" e "[...] simbólico, correspondente ao conjunto de rituais de reconhecimento social, e que compreende o prestígio, a honra etc. O capital simbólico é uma síntese dos demais (cultural, econômico e social)" (THIRY-CHERQUES, 2006, p. 38-39).

Há um constante diálogo, uma contínua interlocução entre campos e agentes sociais. Desse modo, os sistemáticos embates (bem como os lavrados acordos) que dizem respeito à detenção, à valorização e ao intercâmbio dos capitais envolvidos (econômico, cultural, social, simbólico), podem ser compreendidos como processos que permeiam os serviços de água é esgoto. Diante de tal panorama, cada campo social envolvido apresenta interesses que predominam em suas respectivas estruturas. Nesse sentido, tais proveitos correspondem aos agentes sociais que dominam 
o campo. Tal controle está condicionado à posse de capitais. Nesses processos os agentes sociais são semiautônomos (ativos e passivos), incorporam e reproduzem as relações com a estrutura do campo social através dos habitus, ou seja, o fazem por meio de produtos coletivos que orientam suas ações; instrumentos capazes de auxiliar na reflexão acerca da relação (e da mediação) entre as sujeições sociais exteriores e a subjetividade dos agentes sociais (Idem).

É justamente pelos habitus que os agentes sociais interiorizam valores, normas e princípios sociais que asseguram a adequação entre suas ações e a realidade social objetiva (BOURDIEU, 1996). Portanto, o progressivo reconhecimento da necessidade dos serviços de água e esgoto (HOCHMANN, 1998) e os capitais inerentes aos mesmos envolveram (e ainda envolvem) governantes, legisladores, engenheiros, comerciantes, imigrantes, funcionários públicos e, no geral, os usuários dos serviços. Da mesma maneira, instituições (e grupos) como os governos e casas legislativas (federal, estaduais e municipais), sindicatos, corpos funcionais, partidos políticos, empresas (nacionais e estrangeiras; estatais, mistas e privadas) e corporações financeiras. Há uma pluralidade de agentes sociais, habitus e interesses.

Numa diversidade de agentes sociais, habitus e interesses, operam e entrelaçam-se uma significativa quantidade de campos sociais; como por exemplo, os campos político, empresarial, profissional, jurídico entre outros. Assim, nos contextos em que os serviços de água e esgoto são planejados, implantados executados e administrados, os campos sociais vigentes podem ser compreendidos enquanto subcampos (THIRY-CHERQUES, 2006) componentes de um campo num sentido amplo, um campo social Água e Esgoto (AE).

\section{O campo AE: agência, estrutura e poder no Paraná entre 1998 e 2002}

O campo AE resulta do consenso em torno dos serviços de água e esgoto, mas paradoxalmente, apresenta-se como um espaço onde uma numerosidade de agentes sociais trava lutas conforme o modo com que os capitais envolvidos são mobilizados. Nessa contradição, a temática do poder é inerente. Assim, na complexa estrutura do campo AE, também vigora um “campo do poder" que, não sendo "um campo como os outros", constitui-se num "espaço de relações de força entre os diferentes tipos de capital", onde estão presentes "os agentes suficientemente providos de um dos diferentes tipos de capital para poderem dominar o campo 
correspondente", protagonizando conflitos "sempre que o valor relativo dos diferentes tipos de capital é posto em questão" (BOURDIEU, 1996, p. 52). No intuito de controlar os capitais mobilizados e os conflitos vigorantes, o campo do poder pode apresentar uma dupla função, pois assumirá caracteres de conservação ou transformação conforme contextos específicos.

Os serviços de água e esgoto no estado do Paraná oferecem uma interessante reflexão. Ao longo da experiência paranaense dos serviços de água e esgoto, governantes, comerciantes, legisladores, militantes, profissionais entre outros usuários dos ofícios, interagiram com empresas, instituições financeiras, partidos políticos, sindicatos entre outras organizações (sejam governamentais ou não) (SCHUSTER, 1994). O cenário paranaense proporciona subsídios para compreender a Companhia de Saneamento do Paraná (SANEPAR) como uma expressão do campo do poder acerca dos campos sociais (ou subcampos) que formam o campo social AE.

A SANEPAR, a companhia mista (que combina gestões estatais e privadas) responsável pelos serviços de abastecimento de água e coleta de esgoto no estado do Paraná foi fundada em 1963

“[...] com o objetivo de abrir novos horizontes no setor de saneamento, até então estrangulado e carente de recursos face às antiquadas normas adotadas. Por isso, a SANEPAR fixou uma nova política de saneamento, incumbindo-se de estudar, projetar, construir e administrar os serviços de abastecimento de água e sistemas de esgotos sanitários, mediante a efetiva colaboração de entidades municipais"’i.

Assim, uma estrutura da SANEPAR merece atenção: o seu Conselho de Administração (CAd). Conforme o estatuto da empresa, tal departamento tem a função de aprovar, deliberar e retificar iniciativas que dizem respeito à sua atuação enquanto empresa mista (público-privada) nas diversas áreas organizacionais (políticas públicas, contratações, mercado de ações, empréstimos, financiamentos, etc.), bem como eleger os diretores da companhia (SANEPAR, 2012). Desse modo, o CAd da SANEPAR, do alto dos seus crivos burocráticos, é o setor que avaliza as medidas administrativas da empresa; e essas permeiam um universo que envolve interesses políticos contextualmente hegemônicos.

Delimitando o caso paranaense, no intuito de compreender as dinâmicas dos agentes e campos sociais que contemplam aquilo que denominamos de campo social $\mathrm{AE}$, o presente texto buscará uma reflexão acerca das formações profissionais e das trajetórias sociais (LABACHE; SAINT-MARTIN, 2008) dos integrantes do CAd da SANEPAR entre 1998 e 2002. Nesse intervalo, é possível identificar que os dirigentes da companhia orientaram suas decisões junto a uma abertura 
dos ofícios de água e esgoto para o setor privado, juntamente com uma atenção sistemática às ações da empresa no mercado financeiro ${ }^{\mathrm{ii}}$.

Na década de 90, a orientação neoliberal monetarista (MARIANI, 2007), de renegociação de dívidas e ajuste fiscais dos Estados brasileiros, de enfraquecimento de controle estatal (sobretudo no que diz respeito às movimentações do mercado financeiro), consolida-se como principal referência em termos de política econômica (RIGOLON; GIAMBIAGI, 1999). A SANEPAR buscou alinharse sistematicamente a tal realidade. Sob o governo de Jaime Lerneriii, por meio da "Lei Estadual no. 11.963" de dezembro de 1997, o Estado do Paraná obteve a autorização para "alienar ações de sua propriedade no capital social" da SANEPAR, "desde que mantivesse o controle da companhia"iv . No entanto, o conservado controle estatal figurou naquele contexto de uma maneira contraditória, pois a regulamentação por parte do Estado era compreendida enquanto um entrave para uma almejada expansão da empresa junto ao então badalado mercado de ações (Idem).

As decisões efetuadas pela SANEPAR foram formalmente lavradas por seus conselheiros administrativos do CAd. Cada um desses indivíduos (agentes sociais) age na empresa conforme o interesse predominante de seu campo social de origem (BOURDIEU, 1996). Nessa lógica, na gestão que compreende setembro de 1998 e dezembro de 2002, os processos envolvendo dirigentes da SANEPAR revelam um sistemático alinhamento desses à vertente neoliberal vigente na época (MATOS, 2008, p. 207-208). É o que se conclui se prosoprografarmos tais agentes. O termo "prosopografia" pode ser compreendido como "a investigação das características comuns de um grupo de atores na história por meio de um estudo coletivo de suas vidas", e sua finalidade "é dar sentido à ação política”, aclarar "a mudança ideológica ou cultural, identificar a realidade social”, assim como delinear e "analisar com precisão a estrutura da sociedade e o grau e a natureza dos movimentos em seu interior" (STONE, 2011, p. 115-116). Tal metodologia contempla as trajetórias sociais dos agentes em questão.

Tal método é adotado devido ao fato de apresentar instrumentos que podem detalhar os agentes sociais tanto nas suas composições, quanto nas suas atuações públicas. Nesses procedimentos, os habitus podem ser conhecidos e analisados, assim como as origens e as estratégias de cada agente envolvido, junto a seus respectivos campos sociais. 


\section{Os conselheiros do CAd da SANEPAR (1998/2002)}

Contemplando a opção metodológica pela prosopografia, os primeiros agentes sociais que figurarão como objetos são os conselheiros administrativos que estiveram à frente do CAd da SANEPAR entre setembro de 1998 e dezembro de 2002.

O CAd é um setor “composto de no mínimo 5 (cinco) e no máximo 9 (nove) membros”, cabendo ao mesmo "fixar a orientação geral dos negócios da Companhia", assim como "eleger e destituir os diretores", "deliberar, previamente à sua celebração, sobre os contratos" da empresa e gerir burocraticamente o seu patrimônio (SANEPAR, 2012, p. 5). Nessas atribuições, inclui-se a definição de uma "lista tríplice de empresas especializadas em avaliação econômica de empresas para a elaboração de laudo de avaliação das ações da Companhia", a decisão "sobre a proposta de destinação dos lucros do exercício", a aprovação do "plano de cargos e salários, bem como a política salarial da Companhia”, a deliberação "o Orçamento Anual” e as manifestações (favoráveis ou contrárias) "a respeito de qualquer oferta pública de aquisição de ações que tenha por objeto as ações de emissão da Companhia" (Idem, p. 5-6).

Diante das atribuições do CAd da SANEPAR, é possível supor que seus conselheiros administrativos operam tecnocraticamente, "pela via do planejamento" (BRESSER PEREIRA, 1977, p. 80), consolidando uma hierarquia legalmente instituída junto aos serviços de água e esgoto no Paraná. Nesses processos, capitais e, consequentemente, interesses são, sistemática e respectivamente, mobilizados e consolidados.

Portanto cabe perguntar: Quem são os agentes sociais que compõem o CAd da SANEPAR? Quem são os conselheiros administrativos do CAd da SANEPAR? São oriundos de onde? O que fizeram além de administrarem a companhia? Como vivem? O que representam? O que almejam enquanto agentes do campo de poder que regula o campo social AE? Buscaremos responder tais interrogações tendo como referência o período que compreende setembro de 1998 e dezembro de 2002.

Os conselheiros do CAd da SANEPAR (entre 1998 e 2002) podem ser identificados nos campos político (o conjunto de agentes ligados à burocracia estatal e/ou às instituições políticas), empresarial (onde estão presentes as demandas de empreiteiras com vinculação direta e/ou indireta 
junto à SANEPAR), profissional (funcionários de carreira na SANEPAR) jurídico (em especial, advogados e procuradores de Estado) e médico (integrantes de instituições da área de Saúde).

O campo empresarial conta com 4 conselheiros, sendo 1 também do campo político. Os conselheiros desse campo são: Ricardo Coutinho de Senna, José Carlos Irago Garcia, Rodrigo Bhering de Andrade e Ingo Henrique Hübert.

Ricardo Coutinho de Senna é natural de Belo Horizonte - MG, engenheiro civil formado pela Universidade Federal de Minas Gerais (UFMG) e um executivo de carreira ${ }^{\mathrm{v}}$ junto A Construtora Andrade Gutierrez; empresa componente do consórcio Dominó Holdings S/A; um conglomerado empresarial ligado a interesses econômicos transnacionais com participação acionária na SANEPAR. Além da própria Andrade Gutierrez, a Dominó, juntamente com "o grupo francês Vivendi (hoje denominado SANEDO), [...] o Banco Opportunity e a Copel Participações”, representa o braço privado da SANEPAR (SANEPAR, 2003, p. 1).

No currículo de Senna também constam passagens pela Companhia Energética de Minas Gerais (CEMIG), Grupo CCR e "Quiport - Concessionária do Aeroporto Internacional de Quito Equador (concessionária responsável pela construção, operação e gestão do Novo Aeroporto Internacional de Quito - Mariscal Sucre)"vi.

José Carlos Irago Garcia é natural de Madri (Espanha), administrador (formado pela Escola de Comércio de Vigo - Espanha e pelo The London Business School - Inglaterra) e diretor da Dominó $^{\text {vii }}$. Garcia já exerceu cargos em diversas empresas do setor de abastecimento de água. $\mathrm{Na}$ Espanha, especificamente na cidade de Torrelavega, Irago esteve envolvido num escândalo de corrupção acerca "de irregularidades na gestão da empresa mista Aguator" (formada pela Câmara Municipal de Torrelavega e pela Aqualia - uma grande empresa europeia privada de gestão de águas), que era responsável pelo abastecimento de água daquela cidade entre 1999 e $2000^{\text {viii }}$

Rodrigo Bhering de Andrade é formado em Direito pela Universidade de Brasília (UnB) e “diretor de empresas ligadas ao grupo Opportunity"ix . Em 2009, Andrade foi denunciado por envolvimento no "escândalo de propinas e lavagem de dinheiro investigado Operação Satiagraha" da Polícia Federal $(\mathrm{PF})^{\mathrm{x}}$; a qual implicava executivos do Opportunity. O conselheiro teve seu "pedido de prisão decretada, mas, juntamente com os demais executivos do Opportunity, conseguiu 
HC (habeas corpus) concedido por Gilmar Mendes, presidente do STF (Supremo Tribunal Federal) na época"xi.

Entre Senna, Garcia e Andrade há uma característica em comum: os 3 são executivos ligados à Dominó. Enquanto acionista privado da SANEPAR, a Dominó foi beneficiada pela "Lei Estadual no. 11.963" de dezembro de $1997^{\text {xii }}$.

Fechando o campo empresarial, o conselheiro administrativo Ingo Henrique Hübert também ocupou o campo político. As atuações de Hübert nos campos empresarial e político são bem marcantes. Autor do livro "A Estatal eficaz: Mito ou Possibilidade?”xiii, Hübert é natural de Curitiba-PR, graduado em Engenharia Elétrica pela Universidade Federal do Paraná (UFPR) e pósgraduado na mesma área pela Universidade de Stuttgart (Alemanha) e na área de Administração pela Universidade Fontainebleau (França). Ao longo de sua carreira, Hübert ocupou vários cargos em estatais. Entre eles, vice-presidente e diretor de Recursos Humanos da antiga Telecomunicações do Paraná S.A. (TELEPAR), diretor presidente e secretário executivo do Conselho de Administração da Companhia Paranaense de Energia (COPEL), diretor presidente e presidente do CAd da SANEPAR ${ }^{\text {xiv }}$.

$\mathrm{Na}$ iniciativa privada, Hübert foi diretor do Grupo Empresarial Tupi, Joinville, SC, diretor da Indústria Cerâmica Paraná S.A. (INCEPA), diretor Geral da ABS - Indústria de Bombas Centrífugas Ltda. e diretor da Câmara de Comércio Brasil Alemanha ${ }^{\mathrm{xv}}$. Atualmente é dirigente de suas próprias empresas, a Planning International de Engenharia e o Consorcio Powerline ${ }^{\mathrm{xvi}}$, e também é Diretor de Patrimônio da AMIG (Associação Pró-Memória da Imigração Germânica) ${ }^{\text {xvii }}$.

Em termos familiares, seus filhos (e sócios ${ }^{x v i i i}$ ) Ivens Henrique Hübert e Andreas Martin Hübert são, respectivamente, advogado (graduado em Direito pela UFPR e mestre em Direito pela Pontifícia Universidade Católica de São Paulo - PUC-SP ${ }^{\mathrm{xix}}$ ) e engenheiro elétrico formado pela Universidade de São Paulo (USP) e mestre em Finanças pela London Bussiness School

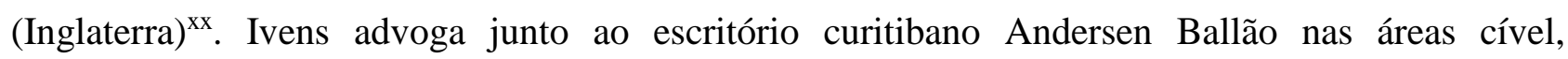
comercial, societário, investimento estrangeiro, importação e exportação, comércio internacional, além de autor dos livros "Sociedade Empresária \& Capital Social" e "Condomínios em geral e Incorporações Imobiliárias"xxi . E Andreas atualmente reside na Inglaterra, mas também já morou na Finlândia, na Alemanha e nos EUA. ${ }^{\text {xii }}$. 
Entre 2001 e 2002, Hübert acumulou os cargos de presidente do CAD da SANEPAR, presidente da COPEL e secretário da Fazenda do Paraná. Nessa época, o conselheiro se envolveu num escândalo que

[...] deu prejuízo de $\mathrm{R} \$ 80$ milhões aos cofres do Estado do Paraná. Uma empresa falida, a Olvepar, vendeu créditos do ICMS para a Copel, a Companhia Paranaense de Energia Elétrica. A Copel comprou os créditos com a autorização da secretaria estadual da Fazenda. Na época, o presidente da Copel era também o secretário da Fazenda do Paraná, Ingo Henrique Hubert ${ }^{x x i i i}$.

Além do caso Olvepar, Hübert também foi pivô num processo que envolveu "a viabilização de um contrato" sem licitação entre a COPEL "e a Associação dos Diplomados da Faculdade de Economia, Administração e Contabilidade da USP (Adifea)”. O contrato custou à estatal R\$ 16,8 milhões:

\begin{abstract}
“[...] o empresário Maurício Roberto Silva, dirigente da Empresa Brasileira de Consultoria (Embracon) [...] teria deixado de recolher R \$ 3,5 milhões em tributos federais (valor sem multa e juros) entre 1998 e 2002. Parte do montante sonegado se referia a um pagamento que o empresário recebeu por serviços prestados para a Associação dos Diplomados da Faculdade de Economia, Administração e Contabilidade da Universidade de São Paulo (Adifea). A entidade foi contratada em outubro de 2002 pela Copel para fazer o levantamento de créditos tributários que poderiam ser compensados. Recebeu $\mathrm{R} \$ 16,8$ milhões pelo serviço. Não houve licitação; na época, a Copel alegou que a Adifea tinha notório saber sobre o assunto, o que dispensava a concorrência. Mas o trabalho foi terceirizado à Embracon, que embolsou quase todo o valor - R\$ 16,6 milhões"xxiv.
\end{abstract}

Hübert foi um dos signatários do "o decreto 6.244/2002, que foi o instrumento legal da compensação de créditos tributários na forma proposta pela Adifea”. Diante de tal cenário, o conselheiro teve prisão decretada em $2004^{\mathrm{xxv}}$.

A atuação político-empresarial de Ingo Henrique Hübert e as ligações diretas dos conselheiros Ricardo Coutinho de Senna, José Irago Garcia e Rodrigo Bhering de Andrade com a Dominó Holdings S/A são evidências de uma significativa sintonia entre os campos político e empresarial no campo AE no período 1998/2002. Tal harmonia indica o empenho do braço privado da SANEPAR em prol da exploração especulativa dos serviços de água e esgoto junto ao mercado financeiro $^{\mathrm{xxvi}}$.

Outro conselheiro que, assim como Hübert, também ocupou espaços no campo político é Giovani Gionédis. Integrando simultaneamente o campo jurídico, Gionédis é curitibano, 
[...] graduado em Direito "pela Universidade Federal do Paraná em 1979. Além de ter uma atividade profissional profícua, ele serviu o Estado do Paraná em muitas funções públicas relevantes. Ele era um assessor legislativo na Assembleia Legislativa do Estado (1987/1988), Procurador-Geral de Curitiba (1989/1994), o secretário de Estado do Paraná (1995/1996), secretário-chefe da Casa Civil do Paraná (1996/1997), Paraná Secretário de Estado da Fazenda (1997/2000), Presidente do Conselho de Administração do Banco do Estado do Paraná - BANESTADO (1997/2000), Presidente do Conselho de Administração do Desenvolvimento Paraná Banco S/A - na dissolução (1997/2000), Presidente do Conselho de Administração da Agência de Desenvolvimento do Paraná S/A (1990/2000), Presidente do Conselho de Investimentos do Fundo de Desenvolvimento Econômico e do Paraná Fundo S/A - FDE (1997/2000) e Presidente do Conselho de Administração da Companhia de Saneamento do Paraná - SANEPAR (1997/2000)’xxvii.

Filho de Adelina Pereira Gionédis e Antenor Gionédis (ex-aluno do Colégio Medianeira de Curitiba e formado em Medicina pela Faculdade Evangélica do Paraná em 1971), Giovani Gionédis é casado com a advogada Louise Rainer Pereira Gionédis; que também é sua sócia no escritório curitibano de advocacia Pereira \& Gionédis. Juntos possuem sociedades "em 3 (três) empresas que acumulam um capital de" R\$ 17.400.000,00 (Dezessete milhões e quatrocentos mil reais), “nos setores imobiliário, financeiro e jurídico"xxviii. Entre seus sócios também está o filho do casal: Giovani Gionédis Filho; que por sua vez é casado com Natália Patrocínio ${ }^{\mathrm{xxix}}$. Praticante de golfe ${ }^{\mathrm{xxx}}$, Gionédis Filho é sócio de "8 (oito) empresas no estado de Paraná e de 2 (duas) em São Paulo. Suas sociedades acumulam o capital de $\mathrm{R} \$ 20.460 .500,00$ (vinte milhões, quatrocentos e sessenta mil e quinhentos reais), "nos setores imobiliário, médico, financeiro e jurídico"xxxi.

Em tais associações, a família Gionédis é sócia de Roberto Cordeiro Justus, atual prefeito de Guaratuba-PR e filho do atual deputado estadual (e também ex-presidente da Assembleia Legislativa do Paraná - ALEP) Nelson Justus ${ }^{x x x i i}$; ambos filiados ao partido "Democratas" $(\mathrm{DEM})^{\mathrm{xxxiii}}$.

Em 4 de setembro de 1998, enquanto presidente do CAd da SANEPAR, Giovani Gionédis (o pai) tomou iniciativas no intuito de fortalecer o setor privado da companhia por meio da Lei Estadual no. 11.963 de 1997, alienando “39,71\% das ações ordinárias para a Dominó Holdings S/A" com preços abaixo dos praticados no mercado (SANEPAR, 2003, p. 1). Assim, a Dominó foi favorecida por meio de um "acordo de acionistas" que "na prática tornou nenhum o poder-dever de controle" do Estado do Paraná, "decorrente de sua participação majoritária no capital social da" SANEPAR ${ }^{\mathrm{xxxiv}}$. No entanto, mesmo com o empoderamento do setor privado, as crises econômicas que se aprofundaram ao final da década de 90 (FILGUEIRAS, 2000) formaram expressivos embaraços ao desempenho da SANEPAR no mercado de ações ${ }^{\mathrm{xxxv}}$. 
A trajetória de Giovani Gionédis nos campos político e jurídico contemplam suas orientações administrativas no CAd da SANEPAR entre 1998 e 1999. Já fora do CAd da SANEPAR, Gionédis esteve à frente da privatização do Banco do Estado do Paraná (BANESTADO) em 2000, sendo condenado, em 2008, a 4 anos e meio de prisão e 1500 salários mínimos de multa por lavagem de dinheiro. O MPF conclui que Gionédis utilizou de maneira fraudulenta a estrutura do banco para viabilizar a realização de uma doação eleitoral não contabilizada, de cerca de $\mathrm{R} \$ 1.000 .000,00$ (um milhão de reais) para a campanha de reeleição do então governador Jaime Lerner no ano de $1998^{\mathrm{xxxvi}}$.

Gionédis rompe com o governo Lerner e se opõe à tentativa de privatização da COPEL em $2001^{\text {xxxvii }}$. O que num primeiro momento pareceu contraditório pode ser relativizado pelo fato de Gionédis ter sido candidato a governador do Paraná nas eleições de 2002 pelo Partido Social Cristão (PSC). No pleito, Gionédis não se elegeu e conquistou 26567 votos $^{\text {xxxviii }}$. Finalizando sua trajetória, em 2015, a empresa de seguros de crédito EBCP (Empresa Brasileira de Consultoria Econômica e Participações Ltda.), de propriedade de Gionédis, esteve envolvida no escândalo de corrupção conhecido como "Lista de Furnas"xxxix .

No campo político, a presença junto aos níveis (municipal, estadual e federal) da burocracia estatal paranaense, seja por meio de relações institucionais via instituições políticas (partidos, federações, sindicatos, associações, etc.) e/ou por meio de relações pessoais e/ou familiares, revelase uma condição significativa para possibilidades de acúmulo de uma variedade de capitais. Nessa lógica, dos 11 agentes que ocuparam o cargo de conselheiro do CAd, 6 compõem o campo político e já assumiram secretarias de Estado no Paraná.

Além de Hübert e Gionédis, outros 4 conselheiros administrativos do CAd da SANEPAR também estiveram à frente de Secretarias de Estado: Miguel Salomão, José Antonio Andreguetto, Armando Martinho Bardou Raggio e Hitoshi Nakamura.

Nascido em 02/12/1938 e falecido em 09/03/2016, Miguel Salomão era natural de Curitiba, graduado em Ciências Sociais pela Pontifícia Universidade do Paraná (PUC/PR), Ciências Econômicas pela Fundação de Estudos Sociais do Paraná (FESP) e pós-graduado em Economia Internacional pela USP. Salomão foi funcionário de carreira do Banco do Brasil (1961/1967), funcionário do Banco Central do Brasil (1967/1990), delegado do Banco Central do Brasil para os estados do Paraná e Santa Catarina (1981/1990), consultor de Política Monetária do Fundo 
Monetário Internacional (FMI) (1991/1994), secretário de Estado da Fazenda (1995/1997), secretário de Estado de Planejamento e Coordenação Geral (1998/2002) e professor do Centro Universitário das Faculdades Associadas de Ensino (UNIFAE) (1968/1998) ${ }^{\mathrm{xl}}$.

Como consultor indicado pelo FMI, Salomão teve participação importante na criação do Banco Central de Angolaxli, a ponto de garantir que seus filhos Miguel Salomão Júnior (advogado com o OAB 267795SP e mestre em Desenvolvimento Econômico pela UFPR) e Fabio Salomão fossem nomeados consultores do Ministério de Finanças do Governo de Angola em $2011^{\text {xlii }}$.

Juntamente com seu filho Fábio, Miguel Salomão esteve envolvido no escândalo acerca da privatização do BANESTADO ${ }^{\text {liii }}$. Em 2004, Salomão foi denunciado pelo Ministério Público Federal (MPF) ${ }^{x l i v}$. No mês de setembro, “o MPF, em duas ocasiões, denunciou outras 72 pessoas, entre doleiros e empresários, por crimes contra o sistema financeiro". Nessa peça, "os expresidentes do Banestado Domingos de Tarço Murta Ramalho e Manoel Campinha Garcia Cid, o [...] Giovani Gionédis, e o ex-secretário de Estado da Fazenda, Miguel Salomão" foram denunciados ${ }^{\mathrm{xlv}}$.

O conselheiro José Antonio Andreguetto também é natural de Curitiba, graduado em Economia pela UFPR. Em seu currículo constam passagens na direção de transportes da Urbanização de Curitiba S/A (URBS), na presidência do Instituto Ambiental do Paraná (IAP), na Secretaria de Estado do Meio Ambiente e Recursos Hídricos (na qual foi secretário estadual na segunda gestão de Jaime Lerner), no Conselho Estadual de Sanidade Agropecuária (CONESA) e no Conselho Nacional do Meio Ambiente (CONAMA). Também presidiu o Conselho de Administração do IAP, o Conselho de Administração da Superintendência de Desenvolvimento de Recursos Hídricos e Saneamento Ambiental (SUDERHSA), o Conselho Estadual do Meio Ambiente (CEMA) e o Conselho de Desenvolvimento do Litoral Paranaense (COLIT) ${ }^{\text {xlvi }}$. Atualmente é presidente da URBS na vigente gestão de Rafael Greca de Macedo, do Partido da Mobilização Nacional (PMN) (PEREIRA; OLIVEIRA, 2017).

Andreguetto esteve à frente da desativação do aterro da Caximba, na periferia de Curitiba$\mathrm{PR}^{\mathrm{xlvii}}$. E no ano de 2011 foi chefe de gabinete do então prefeito de Curitiba-PR Luciano Ducci, do Partido Socialista Brasileiro (PSB). Quando Ducci se elege deputado federal nas eleições de 2014, Andreguetto segue para Brasília e assume a chefia de seu gabinete na Câmara Federal ${ }^{\mathrm{xlviii}}$. Também filiado ao PSB, o atual presidente da URBS chegou a ser cogitado para o cargo de vice-prefeito da 
capital paranaense na chapa de Greca de Macedo nas eleições de $2016^{\text {xlix }}$. Mas a vaga acabou ocupada por Eduardo Pimentel Slaviero (Idem).

Em termos familiares, Jose Antonio Andreguetto é filho de do advogado Christiano Osvaldo Andreguetto, falecido em 2 de abril de 2017 . Christiano assumiu cargo comissionado na Secretaria de Estado da Agricultura e do Abastecimento, em abril de 2007, no segundo governo de Roberto Requião ${ }^{\text {li }}$ do Partido do Movimento Democrático Brasileiro (PMDB) (PARANÁ, 2007), e foi casado com Elizabete Maria Neiva Negrão ${ }^{\text {lii }}$, madrasta do conselheiro.

Outros membros da família Andreguetto estão presentes no funcionalismo público direta e indiretamente. Carlos Alberto Andreguetto (talvez irmão, primo ou sobrinho de José Antonio Andreguetto) é executivo da empresa Solis Tecnologia Ltda. e foi indiciado por peculato, formação de quadrilha e falsidade ideológica em investigação da Operação Sinapse da PF; que apurava desvios de recursos do Instituto Federal do Paraná (IFPR) em 2013 ${ }^{\text {liii }}$. Carlos é casado com Monica Utri Andreguetto $^{\text {liv }}$, que já trabalhou na Prefeitura de Curitiba ${ }^{\text {lv }}$. O filho do casal, Renan Utri Andreguetto é funcionário do IAP ${ }^{\text {lvi }}$.

Rafael Andreguetto ${ }^{\text {lvii }}$ é sobrinho de Carlos e Monica. Rafael é consultor na área de Turismo vinculado à empresa RCL Planejamento e já prestou serviços na Secretaria Estadual de Esporte e Turismo (SEET). "Atualmente é Diretor Executivo da Agência de Desenvolvimento do Turismo Sustentável do Litoral do Paraná (ADETUR LITORAL)"lviii. Matrimoniou-se com a advogada Luciana Maria Negrão Gandra, filha de Elizabete Maria Neiva Negrão Andreguetto. Luciana é atualmente coordenadora de projetos da Fundação Araucária e já trabalhou nos escritórios Bettega, Mafra \& Sperandio Advogados e Abdala, Brandalize \& Gandra Advocacia ${ }^{\text {lix }}$.

Nos levantamentos realizados também identificamos Paulo Andreguetto como médico do Tribunal de Justiça do Paraná (TJ-PR) ${ }^{1 \mathrm{x}}$. Mas diante das fontes disponíveis, também não foi possível identificar o grau de parentesco com Jose Antonio Andreguetto.

Integrante dos campos médico e político, Armando Martinho Bardou Raggio é natural de Itapetininga-SP e formado em Medicina pela UFPR. Raggio também é mestre em Bioética pela Faculdade de Ciências da Saúde da UnB, especialista em Economia da Saúde pela Universidade Estadual de Campinas (UNICAMP), em Saúde Pública pela USP e doutor em Políticas Públicas de Saúde pela Fundação Oswaldo Cruz (FIOCRUZ) ${ }^{1 \mathrm{lxi}}$. 
O currículo de Raggio é vasto tanto no campo médico, quanto no campo político. Ao longo de sua carreira já foi diretor de divulgação da Associação Paranaense de Médicos Residentes (19771978), diretor de Saúde do Departamento de Desenvolvimento Social da Prefeitura Municipal de Curitiba (1979/1983), diretor geral do Hospital Universitário de Brasília (2012), diretor executivo da Fundação de Ensino e Pesquisa em Ciências da Saúde (FEPECS) (desde 2015) e médico legista no Instituto Médico Legal (IML) (desde 1982). Também já exerceu os cargos de assessor da ViceReitoria da UFPR - Projeto Centro de Articulação Docência-Serviço (1987), gerente geral de Assistência Integral a Saúde - Companhia Siderúrgica Nacional (CSN) em Volta Redonda-RJ (1988), assistente de Direção do Centro de Apoio ao Desenvolvimento das Ações Integradas de Saúde - Secretaria da Saúde de São Paulo (1989), assistente de Direção da Coordenadoria dos Institutos de Pesquisa - Secretaria da Saúde de São Paulo (1990) e professor auxiliar de Ensino da Fundação Universidade Regional de Blumenau (FURB) nas disciplinas: Patologia Geral e Saúde Coletiva $(1991)^{1 \mathrm{xii}}$.

Casado com Nathalie Beghin, “economista formada pela Université Libre de Bruxelles (ULB), com mestrado e doutorado em Políticas Sociais pela Universidade de Brasília (UnB)"lxiii, Raggio foi um gestor público que teve intensa atuação na área da saúde; organizando e participando de conferências e eventos, e sendo autor de diversas publicações acadêmicas na área de ciências da saúde, sendo agraciado pela Medalha de Mérito Oswaldo Cruz concedida pelo então presidente Luiz Inácio Lula da Silva, do Partido dos Trabalhadores (PT), e pelo então ministro da Saúde, José Gomes Temporão do $\mathrm{PMDB}^{\text {lxiv }}$.

Na sua trajetória pela administração pública, além de conselheiro do CAd da SANEPAR, Raggio foi Secretário Municipal de Saúde de Curitiba (1992/1994), presidente do Conselho Municipal de Saúde de Curitiba-PR (1992/1994), presidente da Associação Paranaense de Secretários Municipais de Saúde (APASEMS) (1993), presidente do Conselho Nacional de Secretários Municipais de Saúde (CONASEMS) (1994), Secretário de Estado da Saúde do Paraná (1995) presidente do Conselho Nacional de Secretários Estaduais de Saúde (CONASS) (1996) ${ }^{\text {lxv }}$, Secretário Municipal de Saúde da Prefeitura de São José dos Pinhais-PR (2009-2011) ${ }^{\text {lxvi }}$ e Secretário Municipal de Saúde da Prefeitura Municipal de Sorocaba-SP (2013-2014). No município paulista foi formalmente questionado por um cidadão sorocabense sobre seu envolvimento num episódio "que teria ocorrido em 2000, uma suposta prática de apropriação indébita de verbas do 
Fundo Nacional de Saúde (FNS), proveniente do Sistema Único de Saúde (SUS)”. Raggio refutou as acusações ${ }^{1 \mathrm{xvii}}$.

Por fim, o campo político é fechado com a participação de Hitoshi Nakamura. Filiado ao Democratas (DEM) ${ }^{\text {1xviii }}$ e formado em Engenharia Agronômica pela Faculdade de Agricultura da Universidade da Prefeitura de Osaka/Japão, Nakamura também é mestre em Paisagismo pela mesma instituição; na qual integrou o Grupo de Trabalho que analisou os efeitos da poluição sobre a arborização urbana daquela cidade cixix $^{\text {. }}$

Com significativa atuação junto à comunidade japonesa do Paraná e coautor de diversos projetos ligados ao uso do solo e a questão ambiental, entre 1967 e 1969, na Prefeitura de Osaka, Nakamura iniciou a implantação do programa de desenvolvimento e sustentação com propostas ambientais dentro da Prefeitura Municipal de Curitiba em $1970^{\mathrm{lxx}}$. Tal iniciativa o credenciou para os cargos de Secretário Municipal do Meio Ambiente de Curitiba (1989/1996) e Secretário de Estado do Meio Ambiente e Recursos Hídricos (1996/2000) ${ }^{\text {lxxi }}$.

A trajetória social de Nakamura apresenta algumas polêmicas. Em dezembro de 2013, foi condenado a devolver R $\$ 1,5$ milhão aos cofres públicos:

Os gastos realizados no empreendimento "Portal Paisagístico e Complexo Paisagístico e Turístico de Foz do Iguaçu", na gestão do ex-secretário de Meio Ambiente do Estado, Hitoshi Nakamura (1996/2000), foram considerados irregulares pelo Tribunal de Contas do Estado do Paraná (TCE-PR). O pedido de impugnação das despesas, feito pela Segunda Inspetoria de Controle Externo do Tribunal, foi parcialmente aprovado pelo relator do processo, conselheiro Nestor Baptista ${ }^{\text {lxxii }}$.

Em termos familiares é possível encontrar o nome da arquiteta Sandra Mayumi Nakamura $^{\text {lxxiii }}$ que, filiada ao Partido Democrático Trabalhista (PDT) ${ }^{\text {lxxiv }}$ e sócia da empresa Ecotécnica Tecnologia e Consultoria Ltda. ${ }^{1 x x v}$, já prestou consultoria ambiental em diversos municípios brasileiros $^{\text {lxxvi }}$. Nesse sentido, a suposição de tradição familiar no setor ambiental é bem plausível.

As informações biográficas levantadas sobre esses 6 agentes evidencia a importância do campo político no CAd da SANEPAR entre 1998 e 2002. 
O campo profissional completa o CAd da SANEPAR (1998/2002) com os conselheiros Hamilton Aparecido Gimenes e Carlos Afonso Teixeira de Freitas.

Hamilton Aparecido Gimenes é sindicalista, formado em Pedagogia pelo Centro TécnicoEducacional Superior do Oeste Paranaense e funcionário da SANEPAR desde 1983. Foi o conselheiro administrativo escolhido pelo corpo funcional da companhia, sendo reeleito para o cargo em 2003, 2008 e 2011 1 lxxvii.

Gimenes é dirigente da União das Associações de Empregados da SANEPAR $(\text { ASSESA) })^{1 x x v i i i}$. Em 2015 a ASSESA foi alvo de processo que elucidou "irregularidades na contratação" da associação "para o envase de água potável. Embalado em copos plásticos, o produto era distribuído gratuitamente a órgãos públicos, escolas e em eventos promovidos pelo Governo do Estado"1xxix.

O conselheiro Carlos Afonso Teixeira de Freitas é natural de Curitiba-PR e funcionário de carreira na SANEPAR. Formou-se em Engenharia Civil pela UFPR, Engenharia Sanitarista pela USP e já exerceu os cargos de presidente da Associação Brasileira de Engenharia Sanitária e Ambiental (ABES) - Seção Paraná (1981/1983) (1989/1993), diretor-presidente da Associação Brasileira das Empresas Estaduais de Saneamento (AESBE) (1996/1997) e coordenador geral da Coordenação da Região Metropolitana de Curitiba (COMEC) (1988/1989). Além de conselheiro do CAd da SANEPAR de 1998 a 2002, Freitas também acumulou o cargo de "Diretor-Presidente"lxxx da companhia no mesmo período. Ainda na SANEPAR, Freitas foi engenheiro do Setor de Projetos (1970), chefe da Divisão de Produção (1971/1973), superintendente de Operações (1973/1975), coordenador operacional (1975/1979), diretor de operações (1979), diretor técnico (1979/1983), gerente de desenvolvimento técnico (1985/1987) e Superintendente Administrativo (1987/1990) $)^{\text {lxxxi }}$.

Em 2001, Freitas foi inquirido por uma comissão investigativa instaurada na ALEP, cujo objetivo era esclarecer a atuação da Dominó na SANEPAR, após o acordo de acionistas de 1998. Na ocasião:

O presidente da Sanepar, Carlos Afonso Teixeira de Freitas, foi a nocaute na noite de quarta-feira, diante das inquirições da Comissão Especial de Investigação, instaurada na Assembleia Legislativa do Estado para averiguar denúncias de irregularidades na gestão da Sanepar. Teixeira de Freitas entregou o jogo da maracutaia na Sanepar, ao confessar que dentro da estrutura de administração da empresa, cujo acionista majoritário é o Estado do Paraná, com $52 \%$ das ações com direito a voto, quem manda mesmo é o sócio privado, 
denominado Dominó Holdings". [...] o presidente da Sanepar, Carlos Afonso Teixeira de Freitas, jogou a toalha, ao admitir que somente o governo do Estado dava bens em garantia de empréstimo para financiar obras da companhia ${ }^{\text {lxxxii }}$.

Diante da comissão da ALEP, as respostas de Freitas confirmam as intenções e o entendimentos acerca dos representantes dos campos político e empresarial no CAd da SANEPAR; sobretudo em relação à abertura da companhia ao mercado financeiro e, consequentemente, ao fortalecimento da Dominó nas decisões administrativas da empresa mista paranaense. Assim, Freitas cerra o campo profissional no CAd da SANEPAR no período em questão.

\section{Considerações finais}

A partir das informações até então apresentadas, entre 1998 e 2000, a expansão dos serviços de abastecimento de água e coleta de esgoto tinham como pré-requisito os lucros dos acionistas. Nesse raciocínio, a influência do braço privado da SANEPAR, representado pela Dominó Holdings S./A., revela-se na predominante orientação de ofertas das ações da companhia no mercado financeiro. Essa situação evidencia a hegemonia dos campos político e empresarial no campo AE e, consequentemente, na SANEPAR, visto que essa expressa o campo de poder que regulamenta e equilibra os interesses que permeiam o campo AE.

Os conselheiros do CAd da SANEPAR presentes no período em questão apresentaram posições e trajetórias que indicam a significativa harmonia de seus respectivos campos sociais nas decisões da companhia sobre os rumos do planejamento, da implantação e da administração dos ofícios paranaenses de água e esgoto. Tais deliberações dizem respeito aos capitais mobilizados (políticos, econômicos, culturais, técnicos, acadêmicos, familiares, etc.) num contexto onde a importância e a necessidade desses serviços são elementos de um consenso historicamente construído junto à sociedade brasileira (HOCHMAN, 1998).

Enquanto agentes sociais, os conselheiros do CAd da SANEPAR lançaram mão de habitus que configuraram a constante interlocução de seus valores e interesses com a ampla (e complexa estrutura) do campo AE. Nesse sentido, suas respectivas vidas sociais, relações familiares e carreiras profissionais são bem reveladoras. 
É plausível concluir que [...] “a passagem por uma grande école (escola, universidade, centro de formação técnica, etc.) facilitam amplamente o acesso aos grupos dirigentes" (SAINTMARTIN, 2008, p. 50) ${ }^{\text {lxxxiii }}$. Diante de tal conjectura, “[...] as famílias mais ricas se caracterizam por uma «obsessão pela transmissão»; eles gerem com vigilância a educação, as alianças matrimoniais dos filhos, os espaços de residência e de encontro, as relações" (Idem, p. 57). São as escolas em sintonia com as famílias! Para irmos além do senso comum, essa harmonia só é compreendida enquanto tal, à medida que os agentes sociais envolvidos as concebam como estruturas objetivas que contemplam suas diversas estratégias de conservação de posições nos complexos contextos de vivência social.

Portanto, "as trajetórias de mobilidade (ascendente ou descendente) ou de estagnação social, identificando modelos familiais de ascensão social pela via escolar e outros por aliança matrimonial", juntamente com os "percursos menos ascendentes, e mesmo de desqualificação, geralmente ligados à migração" (SAINT-MARTIN et al, 2008, p. 140) formam um conjunto de variáveis que auxiliam na identificação e na compreensão dos habitus dos conselheiros do CAd da SANEPAR, dos seus respectivos posicionamentos nos campos sociais a que pertencem e, consequentemente, das desigualdades reproduzidas.

\section{Referências}

BARROSO, L. R. (2007). "Saneamento básico: competências institucionais da União, estados e municípios". Revista Eletrônica de Direito Administrativo Econômico, ago./set./out., n¹1, p.1-21.

BOURDIEU, P. (1996). Razões práticas: sobre a teoria da ação. Campinas: Papirus.

BRESSER PEREIRA, L. C. (1977). "Notas introdutórias ao modo tecnoburocrático ou estatal de produção". Estudos Cebrap, nº 20, abr/jun, p. 77-109.

COMPANHIA DE SANEAMENTO DO PARANÁ - SANEPAR (2003). Sem medo de defender o interesse público. Disponível em http://www.sanepar.com.br/sanepar/calandrakbx/filesmng.nsf/48E08D0BEF31E0B983257036006B D6AF/\$File/COMUNICADO090704.pdf?OpenElement; acesso em 04/11/2016.

consolidado.

Disponível

(2012).

Estatuto

social

http://site.sanepar.com.br/sites/site.sanepar.com.br/files/perfil_investidores_2012/estatuto_social_2

6032014.pdf; acesso em 30 de outubro de 2016. 
DURKHEIM, E. (2007). As regras do método sociológico. São Paulo: Martin Claret.

FAORO, R. (2001). Os donos do poder - Formação do patronato político brasileiro. Rio de Janeiro: Globo.

FILGUEIRAS, L (2000). História do Plano Real - Fundamentos, impactos e contradições. São Paulo: Biotempo Editorial.

HOCHMAN, G. (1998). A era do saneamento: as bases da política de saúde pública no Brasil. São Paulo: Hucitec/Anpocs.

LABACHE, L.; SAINT-MARTIN, M. (2008). "Fronteiras, trajetórias e experiências de ruptura". Educação e Sociedade, vol 29, n 103, mai/ago, p. 333-354.

MARIANI, E. J. (2007). “A trajetória da implantação do neoliberalismo”. Revista Urutágua, n 13, ago/set/out/nov, p.1-7.

MARQUES, E. C. (1999). "Redes sociais e instituições na construção do Estado e da sua permeabilidade". Revista Brasileira de Ciências Sociais, out., vol. 14, n 41, p. 45-67.

MATOS, H. (2009). Capital social e comunicação: interfaces e articulações. São Paulo: Summus.

MATOS, S. T. S. (2008). "Os conceitos primeiros de neoliberalismo". Mediações, v. 13, n.1-2, jan/jun e jul/dez, p. 192-213.

OLIVEIRA, M. R. (2016). "Grupos políticos dominantes e políticas públicas: um estudo sobre o corpo administrativo da Companhia de Saneamento do Paraná (SANEPAR) entre 2003 e 2014". Revista NEP - Núcleo de Estudos Paranaenses da UFPR, v. 2, nº 2, p. 415-432.

(2016 a). "A família Peretti Gurtensten: indicativos para uma pesquisa sobre empresariado e política paranaense". Revista NEP - Núcleo de Estudos Paranaenses da UFPR, v. 2, $\mathrm{n}^{\mathrm{o}} 2$, p. 81-88.

OLIVEIRA, R. C. (2007). "Famílias, poder e riqueza: redes políticas no Paraná em 2007". Sociologias, jun/dez, n.18, pp.150-169.

. (2012). Na teia do nepotismo: sociologia política das relações de parentesco e poder político no Paraná e no Brasil. Curitiba: Insigth.

PARANÁ (2007). Decreto $n^{o} 458$, de 28 de março de 2007. Nomeação de Christiano Osvaldo Andreguetto, para o cargo de assistente técnico, da Secretaria de Estado da Agricultura e do Abastecimento - SEAB, e exoneração de Fante de Souza Farias. Disponível em http://www.leisestaduais.com.br/pr/decreto-n-458-2007-parana-nomeacao-de-christiano-osvaldoandreguetto-para-o-cargo-de-assistente-tecnico-da-secretaria-de-estado-da-agricultura-e-doabastecimento-seab-e-exoneracao-de-fante-de-souza-farias; acesso em 27/04/2017.

PEREIRA F. M.; OLIVEIRA, M. R. (2017). "Estruturas familiares na Prefeitura Municipal de Curitiba: uma prosopografia do secretariado de primeiro escalão do governo de Rafael Greca de 
Macedo no início de 2017”. Revista NEP - Núcleo de Estudos Paranaenses da UFPR, v.3, n.1, p. 238-267.

RIBEIRO, J. W.; ROOKE, J. M. S. (2010). Saneamento básico e sua relação com o meio ambiente $e$ a saúde. 36 p. Trabalho de Conclusão de Curso do Curso de Especialização em Análise Ambiental. Universidade Federal de Juiz de Fora.

RIGOLON, F.; GIAMBIAGI, F. (1999). "A Renegociação das Dívidas e o Regime Fiscal dos Estados". In: A economia brasileira nos anos 90 / organizadores Fábio Giambiagi, Maurício Mesquita Moreira. Rio de Janeiro: BNDES.

SAINT-MARTIN, M. (2008). "Da reprodução às recomposições das elites: as elites administrativas, econômicas e políticas na França”. TOMO, jul/dez, nº 13, p. 43-73.

; ROCHA, D.C.; HEREDIA, M. (2008). "Trocas intergeracionais e fronteiras sociais na França”. Tempo Social, jun, vol 20, nº 1, p. 135-162.

SCHUSTER, Z. L. L. (1994). Sanepar ano30: resgate da memória do saneamento básico do Paraná. Curitiba: Logos Press.

THIRY-CHERQUES, H. R. (2006). "Pierre Bourdieu: a teoria na prática". Rev. Adm. Pública, vol.40, n.1, pp.27-53.

\section{Documentos de acesso exclusivo em meio eletrônico}

"A Caximba em estado de graça" - Disponível em http://www.gazetadopovo.com.br/vida-ecidadania/a-caximba-em-estado-de-graca-baq4kfdcu8xqwphdv272zdnim; acesso em 27/04/2017.

"A Justiça brasileira: a perplexidade provocada pela Justiça aviltada" - Disponível em http://www.correiodobrasil.com.br/a-justica-brasileira-a-perplexidade-provocada-pela-justicaaviltada/; acesso em 16/10/2016.

"Acordo de acionistas e o princípio da indisponibilidade" - Disponível em http://www.tribunapr.com.br/noticias/acordo-de-acionistas-e-o-principio-da-indisponibilidade/; acesso em 09/07/2017.

“Advogados / Ivens Henrique Hübert" - Disponível em http://www.andersenballao.com.br/author/ivens-henrique-hubert/; acesso em 17/07/2017.

“Água contaminada” - Disponível em http://www.zebeto.com.br/aguacontaminada/\#.WA7zkeUrLIU; acesso em 25/10/2016.

“Andreas Martin Hübert” - Disponível em https://www.facebook.com/andreas.huebert; acesso em $17 / 07 / 2017$. 
"Andregueto na chefia de gabinete de Luciano Ducci" - Disponível em http://www.fabiocampana.com.br/2011/01/andreguetto-na-chefia-de-gabinete-de-luciano-ducci/; acesso em 27/04/2017.

"Armando Martinho Bardou Raggio" - $\quad$ Disponível em https://www.escavador.com/sobre/1190152/armando-martinho-bardou-raggio; $\quad$ acesso em $15 / 07 / 2017$.

“ARMANDO RAGGIO: MEDALHA DE MÉRITO OSVALDO CRUZ” - Disponível em http://jogodopoderparana.com.br/2009/11/armando-raggio-medalha-de-merito-osvaldo-cruz.html; acesso em 15/07/2017.

"Autuações fiscais do caso Banestado chegam a mais de R\$ 8 bilhões" - Disponível em http://www.prpr.mpf.mp.br/news/23-02-2011-autuacoes-fiscais-do-caso-banestado-chegam-a-maisde-r-8-bilhoes; acesso em 12/10/2016.

"Carlos Andreguetto" - Disponível em https://www.facebook.com/carlos.andreguetto.7; acesso em 27/04/2017.

"Companheiro Hamilton continua no CAd" - Disponível em http://saemac.blogspot.com.br/2011/04/companheiro-hamilton-continua-no-cad.html; acesso em $16 / 07 / 2017$.

"Curriculum of Giovani Gionédis" - $\quad$ Disponível em http://www.pereiragionedis.com.br/eng/advogado.php?codigo=11; acesso em 23/11/2016.

"Diário PR - $\quad$ Tribunal de Justiça" - $\quad$ Disponível em http://www.radaroficial.com.br/d/6356314003341312; acesso em 22/01/2017.

"Diretoria e Conselhos / Conselho de administração" - Disponível em http://ri.ccr.com.br/grupoccr/web/conteudo_pt.asp?idioma=0\&tipo=47156\&conta=28\#2; acesso em 25/12/2016

"Diretoria" - Disponível em http://www.amigbrasil.org.br/Quem-Somos/Diretoria; acesso em 13/07/2017.

"Empresário é condenado no caso Copel-Adifea" - Disponível em http://www.gazetadopovo.com.br/vida-publica/empresario-e-condenado-no-caso-copel-adifeabg4kpz8hldij5uolzcs9v9qvi; acesso em 13/07/2017.

"Ex-prefeito Ivan sofre dois bloqueios judiciais" - Disponível em http://www.cristianolima.com/2015/10/ex-prefeito-ivan-sofre-dois-bloqueios-judiciais/; acesso em 15/10/2016.

"FALECIMENTOS DO DIA (02/04/2017)" - $\quad$ Disponível em http://www.tribunapr.com.br/noticias/falecimentos/falecimentos-02042017/; acesso em 27/04/2017. 
"Fraude na Copel foi ao ar em rede nacional no Fantástico, da TV Globo" - Disponível em http://www.historico.aen.pr.gov.br/modules/noticias/article.php?storyid=39843; $\quad$ acesso em 13/072017.

"Giovani Gionedis (2002)" - Disponível em https://noticias.uol.com.br/politica/politicosbrasil/2002/governador/1141955-giovani-gionedis.jhtm; acesso em 10/07/2017.

"GIOVANI GIONEDIS FILHO" - $\quad$ Disponível em http://meucongressonacional.com/eleicoes2014/empresa/WZGJHLHLGIX; acesso em 08/11/2016.

“Giovani Gionédis Filho" - Disponível em http://www.consultasocio.com/q/sa/giovani-gionedisfilho; acesso em 08/11/2016.

"Giovani Gionédis Filho" - $\quad$ Disponível em https://cbg.bluegolf.com/bluegolf/cbg16/event/cbg1611/contest/1/profile/ggionedisfil/tresults.htm; acesso em 09/07/2017.

"Giovani Gionédis" - Disponível em http://www.consultasocio.com/q/sa/giovani-gionedis; acesso em 08/11/2016.

"HITOSHI NAKAMURA é filiado[a] ao DEM - DEMOCRATAS desde 01/10/1997 na cidade de CURITIBA - PR (zona/seção: $177 \quad$ - 79 )” $\quad$ - Disponível em http://eleicoesepolitica.com/filiado/_perfil/dados/PR/000761940604; acesso em 16/07/2017.

"Hitoshi Nakamura terá de devolver R\$ 1,5 milhão, confirma TCE" - Disponível em http://www1.tce.pr.gov.br/noticias/ex-secretario-hitoshi-nakamura-tera-de-devolver-r\$-15-milhaoconfirma-tce/2278/N; acesso em 12/10/2016.

“Índice dos Diários da República de Angola - I Série - 2011" - Disponível em http://www.audiconta-angola.com/?page_id=995; acesso em 12/10/2016.

"INESC / Quem somos / Equipe / Colegiado de Gestão" - Disponível em http://www.inesc.org.br/quem-somos/equipe; acesso em 15/10/2016.

"Ingo Henrique Hübert" - Disponível em http://www.consultasocio.com/q/sa/ingo-henrique-hubert; acesso em 17/07/2017.

"Investigação inaugura banco de dados contra o crime organizado" - Disponível em http://www.fetecpr.org.br/investigacao-organiza-banco-de-dados-contra-o-crime-organizado/; acesso em 11/10/2016.

"Jaime Lerner" - $\quad$ Disponível em http://www.casacivil.pr.gov.br/modules/conteudo/conteudo.php?conteudo=91; $\quad$ acesso em 21/11/2016.

"Justiça condena Giovani Gionédis a 4 anos e meio de prisão" - Disponível em http://www.tribunapr.com.br/noticias/politica/justica-condena-giovani-gionedis-a-4-anos-e-meiode-prisao/; acesso em 10/07/2017. 
"Legados de Siguel Salomão" $\quad$ - $\quad$ Disponível em http://www.gazetadopovo.com.br/opiniao/artigos/legados-de-miguel-salomao-

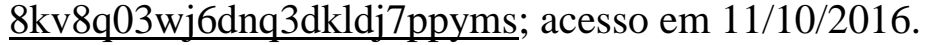

"Liminar suspende o leilão de privatização da Copel" - Disponível em http://www1.folha.uol.com.br/folha/dinheiro/ult91u34028.shtml; acesso em 10/07/2017.

"Lista de Furnas conecta Aécio, Banestado, Youssef e...Sérgio Moro" - Disponível em http://www.tijolaco.com.br/blog/lista-de-furnas-conecta-aecio-banestado-youssef-e-sergio-moro/; acesso em 10/07/2017.

"LIVRO: A Estatal Eficaz - Mito ou Possibilidade?" - Disponível em https://www.sebosonline.com.br/produto/864035/ingo-henrique-hubert-a-estatal-eficaz-mito-oupossibilidade; acesso em 17/07/2017.

"Louise Rainer Pereira Gionédis" - Disponível em http://www.consultasocio.com/q/sa/louiserainer-pereira-gionedis; acesso em 08/11/2016.

"Luciana Gandra Andreguetto" - Disponível em https://www.facebook.com/luciana.gandra.9; acesso em 27/04/2017.

"Meio século de saneamento no Paraná" - Disponível em http://site.sanepar.com.br/noticias/meioseculo-de-historia-do-saneamento-no-parana; acesso em 13/10/2016.

“Monica Utri” - Disponível em https://www.facebook.com/monica.utri; acesso em 27/04/2017.

"MPF denuncia Dantas e aponta ligação do Opportunity com valerioduto" - Disponível em https://politicaetica.com/category/rodrigo-bhering-andrade/; acesso em 16/10/2016.

"MPF no Paraná denuncia 62 por crimes financeiros" - Disponível em http://www.tribunapr.com.br/noticias/politica/mpf-no-parana-denuncia-62-por-crimes-financeiros/; acesso em 11/10/2016.

"MPF recebe denúncias contra o secretário municipal de Saúde" - Disponível em http://www.jornalcruzeiro.com.br/materia/496146/mpf-recebe-denuncias-contra-o-secretariomunicipal-da-saude; acesso em 15/10/2016.

"MPF/SP denuncia Dantas por lavagem de dinheiro e mais três crimes" - Disponível em http://www.blogdoporfirio.com/2009/07/mpfsp-denuncia-dantas-por-lavagem-de.html; acesso em 17/10/2016.

"Nelson Justus participa da Posse do novo Secretário de Administração de Guaratuba, Roberto Cordeiro Justus" $\quad-\quad$ Disponível em http://www.nelsonjustus.com.br/index.php?Secao=Nelson.Mostra\&news=1178; $\quad$ acesso $\quad$ em 09/07/2017. 
"O que se passa na sociedade" - Disponível em http://www.gazetadopovo.com.br/vida-ecidadania/colunistas/juril-carnasciali/o-que-se-passa-na-sociedade-3h99s3a8qx94rdofspvd0loi6; acesso em 17/07/2017.

"Portfólio" - Disponível em http://www.ecotecnica.com.br/portfolio.asp; acesso em 16/07/2017.

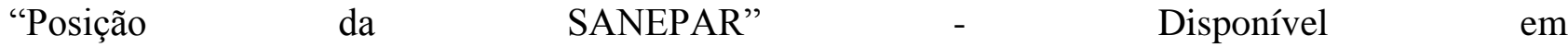
http://www.saneamentobasico.com.br/portal/index.php/arquivo/posicao-da-sanepar/; acesso em 06/11/2016.

"Presos denunciados no caso Copel/Adifea" - Disponível em http://www.tribunapr.com.br/noticias/politica/presos-denunciados-no-caso-copeladifea/; acesso em 13/07/2017.

"PROCESSO: CVM No RJ 2001/11250 (RC No 3889/2002)" - Disponível em http://www.cvm.gov.br/export/sites/cvm/decisoes/anexos/0001/3889-0.pdf; acesso em 17/07/2017.

“programação2.pdf (Versão 1.0)"

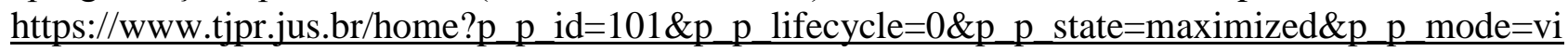
ew\&_101_struts_action=\%2Fasset_publisher\%2Fview_content\&_101_returnToFullPageURL=\%2 $\underline{F} \&$ 101_assetEntryId=5423009\& 101 type=document\&redirect=https\%3A\%2F\%2Fwww.tjpr.jus. br\%2Fhome $\% 3 F p \_p \_i d \% 3 D 3 \% 26 p \_p \_l i f e c y c l e \% 3 D 0 \% 26 p \_p \_s t a t e \% 3 D m a x i m i z e d \% 26 p \_p \_m o d$ e\%3Dview\%26_3_groupId\%3D0\%26_3 keywords\%3DAndreguetto\%26_3_struts_action\%3D\%25 2Fsearch\%252Fsearch\%26_3_redirect\%3D\%252F; acesso em 27/04/2017.

"Rafael Andreguetto" - Disponível em http://www.rclplanejamento.com.br/rafael-andreguetto/; acesso em 27/04/2017.

"Rafael Andreguetto" - Disponível em https://www.facebook.com/rafael.andreguetto?pnref=lhc; acesso em 27/04/2017.

"Relatório (Operação Sinapse)" - Disponível em https://pt.slideshare.net/arykara7002/relatoriosinapse; acesso em 27/04/2017.

"Renan Adreguetto" - Disponível em https://www.facebook.com/renan.andreguetto?fref=ts; acesso em 27/04/2017.

"SANDRA MAYUMI NAKAMURA é filiado[a] ao PDT - PARTIDO DEMOCRÁTICO TRABALHISTA desde 04/01/1994 na cidade de CURITIBA - PR (zona/seção: 177 - 79)" Disponível em http://eleicoesepolitica.com/filiado/_perfil/dados/PR/062016930680; acesso em 16/07/2017.

"Sandra Mayumi Nakamura" - Disponível em http://www.consultasocio.com/q/sa/sandra-mayuminakamura; acesso em 16/07/2017.

"Sanepar adia oferta global de ações preferenciais" - Disponível em http://www.valor.com.br/arquivo/283663/sanepar-adia-oferta-global-de-acoes-preferenciais; acesso em 23/11/2016. 
"Sanepar começa a vender ações até julho" - Disponível em http://www.folhadelondrina.com.br/economia/sanepar-comeca-a-vender-acoes-ate-julho59200.html; acesso em 18/07/2017.

"Secretaria de Meio Ambiente faz contrato milionário de consultoria Estado faz licitação para medicamentos e serviços laboratoriais - $\quad$ Disponível em http://conexaoto.com.br/2014/11/14/secretaria-de-meio-ambiente-faz-contrato-milionario-deconsultoria-estado-faz-licitacao-para-medicamentos-e-servicos-laboratoriais; acesso em 16/07/2017

"Serviço Público Federal / Comissão de Valores Mobiliários (CVM) / Informações Anuais (IAN) 1998 - Sanepar" $\quad$ - $\quad$ Disponível em http://www.sanepar.com.br/sanepar/calandrakbx/filesmng.nsf/9DF5CFCB98487930832572960046 578C/\$File/IAN1998.pdf?OpenElement; acesso em 04/09/2016.

"Serviço Público Federal / Comissão de Valores Mobiliários (CVM) / Informações Anuais (IAN) 1999 - $\quad$ Sanepar" $\quad-\quad$ Disponível em http://www.sanepar.com.br/sanepar/calandrakbx/filesmng.nsf/4B4BD89BEEACD57083257296004 65883/\$File/IAN1999.pdf?OpenElement; acesso em 09/09/2016.

"Serviço Público Federal / Comissão de Valores Mobiliários (CVM) / Informações Anuais (IAN) $2000 \quad-\quad$ Sanepar" $\quad$ - $\quad$ Disponível em https://site.sanepar.com.br/sites/site.sanepar.com.br/files/investidores_rel_ian_dfp_itr/ian-dfpitr/rel_IAN2000-12-30.pdf; acesso em 13/07/2017.

"Serviço Público Federal / Comissão de Valores Mobiliários (CVM) / Informações Anuais (IAN) 2002 - Sanepar" - $\quad$ Disponível em http://www.sanepar.com.br/sanepar/calandrakbx/filesmng.nsf/ABF593B2D91E8029832572960046 5B3F/\$File/IAN2002.pdf?OpenElement; acesso em 27/04/2017.

“Sobre a associação / Diretoria / Gestão 2014/2017” Disponível em http://assesa.sanepar.com.br/institucional; acesso em 25/10/2016.

"Trajetória" - Disponível em http://www.robertorequiao.com.br/trajetoria-2/; acesso em 23/11/2016.

"Um japonês contribuindo para o verde de Curitiba" - Disponível em http://www.asiacomentada.com.br/2014/06/um-japons-contribuindo-para-o-verde-de-curitiba/; acesso em 12/10/2016.

"Varios directivos de Aqualia, imputados en el caso del 'escándalo del agua" - Disponível em http://www.eldiariomontanes.es/20090503/torrelavega/noticias/varios-directivos-aqualiaimputados-20090503.html; acesso em 10/10/2016.

"Vice de Greca será do PSB" 0 Disponível em http://www.esmaelmorais.com.br/2016/07/vice-degreca-sera-do-psb/; acesso em 27/04/2017. 
i Disponível em http://site.sanepar.com.br/noticias/meio-seculo-de-historia-do-saneamento-no-parana; acesso em 13/10/2016.

ii Disponível em http://www.folhadelondrina.com.br/economia/sanepar-comeca-a-vender-acoes-ate-julho-59200.html; acesso em 18/07/2017.

iii "Jaime Lerner, nascido em Curitiba em 17 de dezembro de 1937 é arquiteto e planejador urbano, formado pela Escola de Arquitetura da Universidade Federal do Paraná em 1964. Responsável pela criação e estruturação do Instituto de Planejamento Urbano de Curitiba (Ippuc) em 1965, participou do desenvolvimento do Plano Diretor de Curitiba que resultou no processo de transformação física, econômica e cultural da cidade. Foi prefeito de Curitiba em três mandatos: nos períodos de 1971/75, de 1979/83 e de 1989/92". Disponível em http://www.casacivil.pr.gov.br/modules/conteudo/conteudo.php?conteudo=91; acesso em 21/11/2016.

iv Disponível em http://www.tribunapr.com.br/noticias/acordo-de-acionistas-e-o-principio-da-indisponibilidade/; acesso em 09/07/2017.

http://www.sanepar.com.br/sanepar/calandrakbx/filesmng.nsf/9DF5CFCB98487930832572960046578C/\$File/IAN199 8.pdf?OpenElement; acesso em 04/09/2016.

vi Disponível em http://ri.ccr.com.br/grupoccr/web/conteudo_pt.asp?idioma=0\&tipo=47156\&conta=28\#2;acesso em 25/12/2016.

vii

Disponível

em

http://www.sanepar.com.br/sanepar/calandrakbx/filesmng.nsf/9DF5CFCB98487930832572960046578C/\$File/IAN199 8.pdf?OpenElement; acesso em 04/09/2016.

viii http://www.eldiariomontanes.es/20090503/torrelavega/noticias/varios-directivos-aqualia-imputados-20090503.html; acesso em 10/10/2016

ix Disponível em http://www.blogdoporfirio.com/2009_07_01_archive.html; acesso em 17/10/2016.

${ }^{x}$ Disponível em https://politicaetica.com/category/rodrigo-bhering-andrade/; acesso em 16/10/2016.

xi Disponível em http://www.correiodobrasil.com.br/a-justica-brasileira-a-perplexidade-provocada-pela-justicaaviltada/; acesso em 16/10/2016.

xii Disponível em http://www.folhadelondrina.com.br/economia/sanepar-comeca-a-vender-acoes-ate-julho-59200.html; acesso em 18/07/2017

xiii Disponível em https://www.sebosonline.com.br/produto/864035/ingo-henrique-hubert-a-estatal-eficaz-mito-oupossibilidade; acesso em 17/07/2017.

xiv Disponível em https://site.sanepar.com.br/sites/site.sanepar.com.br/files/investidores_rel_ian_dfp_itr/ian-dfpitr/rel IAN2000-12-30.pdf; acesso em 13/07/2017.

http://www.sanepar.com.br/sanepar/calandrakbx/filesmng.nsf/9DF5CFCB98487930832572960046578C/\$File/IAN199

8.pdf?OpenElement; acesso em 04/09/2016.

${ }^{\text {xvi }}$ Disponível em http://www.consultasocio.com/q/sa/ingo-henrique-hubert; acesso em 17/07/2017.

xvii Disponível em http://www.amigbrasil.org.br/Quem-Somos/Diretoria; acesso em 13/07/2017.

xviii Disponível em http://www.consultasocio.com/q/sa/ingo-henrique-hubert; acesso em 17/07/2017.

xix Disponível em http://www.andersenballao.com.br/author/ivens-henrique-hubert/; acesso em 17/07/2017.

${ }^{x x}$ Disponível em https://www.facebook.com/andreas.huebert; acesso em 17/07/2017.

xxi Disponível em http://www.andersenballao.com.br/author/ivens-henrique-hubert/; acesso em 17/07/2017.

xxii Disponível em https://www.facebook.com/andreas.huebert; acesso em 17/07/2017.

xxiii Disponível em http://www.historico.aen.pr.gov.br/modules/noticias/article.php?storyid=39843; acesso em 13/072017.

xxiv Disponível em http://www.gazetadopovo.com.br/vida-publica/empresario-e-condenado-no-caso-copel-adifeabg4kpz8hldij5uolzcs9v9qvi; acesso em 13/07/2017.

xxv Disponível em http://www.tribunapr.com.br/noticias/politica/presos-denunciados-no-caso-copeladifea/; acesso em 13/07/2017.

xxvi Disponível em http://www.cvm.gov.br/export/sites/cvm/decisoes/anexos/0001/3889-0.pdf; acesso em 17/07/2017.

xxvii Disponível em http://www.pereiragionedis.com.br/eng/advogado.php?codigo=11; acesso em 23/11/2016.

xxviii Disponível em http://www.consultasocio.com/q/sa/giovani-gionedis; acesso em 08/11/2016 e http://www.consultasocio.com/q/sa/louise-rainer-pereira-gionedis; acesso em 08/11/2016

xxix Disponível em http://www.gazetadopovo.com.br/vida-e-cidadania/colunistas/juril-carnasciali/o-que-se-passa-nasociedade-3h99s3a8qx94rdofspvd0loi6; acesso em 17/07/2017.

xxx Disponível em https://cbg.bluegolf.com/bluegolf/cbg16/event/cbg1611/contest/1/profile/ggionedisfil/tresults.htm; acesso em 09/07/2017.

xxxi Disponível em http://www.consultasocio.com/q/sa/giovani-gionedis-filho; acesso em 08/11/2016. 
xxxii Disponível em http://www.nelsonjustus.com.br/index.php?Secao=Nelson.Mostra\&news=1178; acesso em 09/07/2017.

xxxiii Em 2014, Giovani Gionedis Filho doou R\$22.500,00 (vinte e dois mil e quinhentos reais) à campanha do deputado estadual Nelson Justus (DEM), e R \$ 4.000,00 (quatro mil reais) à campanha do governador Beto Richa do Partido da $\begin{array}{lllll}\text { Social Democracia } & \text { Brasileira } & \text { (PSDB). } & \text { Disponível em }\end{array}$ http://meucongressonacional.com/eleicoes2014/empresa/WZGJHLHLGIX; acesso em 08/11/2016).

xxxiv Disponível em http://www.tribunapr.com.br/noticias/acordo-de-acionistas-e-o-principio-da-indisponibilidade/; acesso em 23/11/2016.

xxxv Disponível em http://www.valor.com.br/arquivo/283663/sanepar-adia-oferta-global-de-acoes-preferenciais; acesso em 23/11/2016.

xxxvi Disponível em http://www.tribunapr.com.br/noticias/politica/justica-condena-giovani-gionedis-a-4-anos-e-meio-deprisao/; acesso em 10/07/2017.

xxxvii Disponível em http://www1.folha.uol.com.br/folha/dinheiro/ult91u34028.shtml; acesso em 10/07/2017.

xxxviii Disponível em https://noticias.uol.com.br/politica/politicos-brasil/2002/governador/1141955-giovanigionedis.jhtm; acesso em 10/07/2017.

xxxix Disponível em http://www.tijolaco.com.br/blog/lista-de-furnas-conecta-aecio-banestado-youssef-e-sergio-moro/; acesso em 10/07/2017.

$\mathrm{xl}$

Disponível

em

http://www.sanepar.com.br/sanepar/calandrakbx/filesmng.nsf/4B4BD89BEEACD5708325729600465883/\$File/IAN19 99.pdf?OpenElement; acesso em 09/09/2016.

xli Disponível em http://www.gazetadopovo.com.br/opiniao/artigos/legados-de-miguel-salomao8kv8q03wj6dnq3dkldj7ppyms; acesso em 11/10/2016.

xlii Disponível em http://www.audiconta-angola.com/?page_id=995; acesso em 12/10/2016.

xliii Disponível em http://www.fetecpr.org.br/investigacao-organiza-banco-de-dados-contra-o-crime-organizado/; acesso em 11/10/2016

xliv Disponível em http://www.tribunapr.com.br/noticias/politica/mpf-no-parana-denuncia-62-por-crimes-financeiros/; acesso em 11/10/2016.

xlv Disponível em http://www.prpr.mpf.mp.br/news/23-02-2011-autuacoes-fiscais-do-caso-banestado-chegam-a-maisde-r-8-bilhoes; acesso em 12/10/2016.

xlvi

Disponível

em

http://www.sanepar.com.br/sanepar/calandrakbx/filesmng.nsf/ABF593B2D91E80298325729600465B3F/\$File/IAN200 2.pdf?OpenElement; acesso em 27/04/2017.

xlvii Disponível em http://www.gazetadopovo.com.br/vida-e-cidadania/a-caximba-em-estado-de-gracabaq4kfdcu8xqwphdv272zdnim; acesso em 27/04/2017.

xlviii Disponível em http://www.fabiocampana.com.br/2011/01/andreguetto-na-chefia-de-gabinete-de-luciano-ducci/; acesso em 27/04/2017.

xlix Disponível em http://www.esmaelmorais.com.br/2016/07/vice-de-greca-sera-do-psb/; acesso em 27/04/2017.

${ }^{1}$ Disponível em http://www.tribunapr.com.br/noticias/falecimentos/falecimentos-02042017/; acesso em 27/04/2017.

li "Roberto Requião de Mello e Silva nasceu em 5 de março de 1941, em Curitiba (Paraná), filho do médico e exprefeito de Curitiba Wallace Thadeu de Mello e Silva e Lucy Requião de Mello e Silva. Casado com Maristela Quarenghi de Mello e Silva, pai de Maurício Thadeu e Roberta. Formado em Direito pela Universidade Federal do Paraná e em Jornalismo pela Pontifícia Universidade Católica do Paraná, cursou Urbanismo pela Fundação Getúlio Vargas. [...] Sempre pelo PMDB, foi Deputado Estadual (1983-85), Prefeito de Curitiba (1986-89), Secretário do Desenvolvimento Urbano do Estado do Paraná (1989-90), Governador do Paraná (1991-95), Senador da República (1995-2002), Governador do Paraná (2003-2007) e eleito novamente Governador (2007-2011). Em uma nova disputa por uma vaga no Senado Federal, foi eleito para um mandato de oito anos, cargo que ocupa atualmente". Disponível em http://www.robertorequiao.com.br/trajetoria-2/; acesso em 23/11/2016.

lii Disponível em http://www.radaroficial.com.br/d/6356314003341312; acesso em 22/01/2017.

liii Disponível em https://pt.slideshare.net/arykara7002/relatorio-sinapse; acesso em 27/04/2017.

liv Disponível em https://www.facebook.com/carlos.andreguetto.7; acesso em 27/04/2017.

${ }^{\text {lv }}$ Disponível em https://www.facebook.com/monica.utri; acesso em 27/04/2017.

lvi Disponível em https://www.facebook.com/renan.andreguetto?fref=ts; acesso em 27/04/2017.

lvii Disponível em https://www.facebook.com/rafael.andreguetto?pnref=lhc; acesso em 27/04/2017.

lviii Disponível em http://www.rclplanejamento.com.br/rafael-andreguetto/; acesso em 27/04/2017.

lix Disponível em https://www.facebook.com/luciana.gandra.9; acesso em 27/04/2017. $\mathrm{lx}$ 
tion $=\% 2$ Fasset publisher $\% 2 F v i e w$ content\& 101 returnToFullPageURL $=\% 2 F \& \quad 101$ assetEntryId $=5423009 \& \quad 101 \_t$ ype=document\&redirect=https\%3A\%2F\%2Fwww.tjpr.jus.br\%2Fhome\%3Fp_p_id\%3D3\%26p_p_lifecycle\%3D0\%26p _p state\%3Dmaximized\%26p_p mode\%3Dview\%26_3 groupId\%3D0\%26 3 keywords\%3DAndreguetto\%26_3_stru ts_action\%3D\%252Fsearch\%252Fsearch\%26_3_redirect\%3D\%252F; acesso em 27/04/2017.

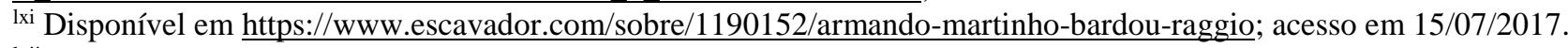
lxii

http://www.sanepar.com.br/sanepar/calandrakbx/filesmng.nsf/ABF593B2D91E80298325729600465B3F/\$File/IAN200 2.pdf?OpenElement; acesso em 27/04/2017.

lxiii Disponível em http://www.inesc.org.br/quem-somos/equipe; acesso em 15/10/2016

lxiv Disponível em http://jogodopoderparana.com.br/2009/11/armando-raggio-medalha-de-merito-osvaldo-cruz.html; acesso em 15/07/2017.

$1 \mathrm{xv}$

Disponível

em

http://www.sanepar.com.br/sanepar/calandrakbx/filesmng.nsf/ABF593B2D91E80298325729600465B3F/\$File/IAN200 2.pdf?OpenElement; acesso em 27/04/2017.

Ixvi Em 2015 foi acusado de desvio de recursos públicos do município de São José dos Pinhais, na "Ação Civil Pública proposta pelo Ministério Público do Estado do Paraná (...) no intuito de nulificar 21 procedimentos de dispensa de licitação firmados com 'Coopergs', 'BMJ' e 'Viva Saúde' entre 2009 e 2011', tendo seus bens bloqueados. Disponível em http://www.cristianolima.com/2015/10/ex-prefeito-ivan-sofre-dois-bloqueios-judiciais/; acesso em 15/10/2016.

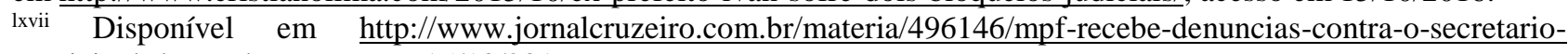
municipal-da-saude; acesso em 15/10/2016.

Ixviii Disponível em http://eleicoesepolitica.com/filiado/_perfil/dados/PR/000761940604; acesso em 16/07/2017. lxix

$$
\text { Disponível }
$$

http://www.sanepar.com.br/sanepar/calandrakbx/filesmng.nsf/4B4BD89BEEACD5708325729600465883/\$File/IAN19 99.pdf?OpenElement; acesso em 09/09/2016.

${ }_{\text {Ixx }}$ Atuação destacada em iniciativas denominadas ambientalmente sustentáveis: "É dele o plano do estabelecimento de uma rede de ônibus na forma de uma teia de aranha, que liga as avenidas radiais com linhas de ligação e paradas dos veículos, que também servem como centros para coleta de lixo reciclável, onde é trocado por plantas". Disponível em http://www.asiacomentada.com.br/2014/06/um-japons-contribuindo-para-o-verde-de-curitiba/; acesso em 12/10/2016. Ixxi Disponível a http://www.sanepar.com.br/sanepar/calandrakbx/filesmng.nsf/4B4BD89BEEACD5708325729600465883/\$File/IAN19 99.pdf?OpenElement; acesso em 09/09/2016.

Ixxii Disponível em http://www1.tce.pr.gov.br/noticias/ex-secretario-hitoshi-nakamura-tera-de-devolver-r\$-15-milhaoconfirma-tce/2278/N; acesso em 12/10/2016.

Ixxiii Nas fontes pesquisadas não foi possível estabelecer, precisamente, o grau de parentesco entre Sandra e Hitoshi Nakamura.

lxxiv Disponível em http://eleicoesepolitica.com/filiado/_perfil/dados/PR/062016930680; acesso em 16/07/2017.

lxxv Disponível em http://www.consultasocio.com/q/sa/sandra-mayumi-nakamura; acesso em 16/07/2017.

lxxvi Disponível em http://conexaoto.com.br/2014/11/14/secretaria-de-meio-ambiente-faz-contrato-milionario-deconsultoria-estado-faz-licitacao-para-medicamentos-e-servicos-laboratoriais; $\quad$ acesso $\quad$ em $\quad 16 / 07 / 2017$ e http://www.ecotecnica.com.br/portfolio.asp; acesso em 16/07/2017.

lxxvii Disponível em http://saemac.blogspot.com.br/2011/04/companheiro-hamilton-continua-no-cad.html; acesso em 16/07/2017.

Ixxviii Disponível em http://assesa.sanepar.com.br/institucional; acesso em 25/10/2016.

Ixxix Disponível em http://www.zebeto.com.br/agua-contaminada/\#.WA7zkeUrLIU; acesso em 25/10/2016.

Ixxx Conforme o estatuto da SANEPAR, "as atribuições" do "Diretor-Presidente" são: a) convocar e presidir as reuniões da Diretoria Executiva; b) propor matérias ao Conselho de Administração; c) coordenar as atividades de auditoria interna; d) acompanhar a programação executiva e a avaliação final dos resultados; e) desenvolver e coordenar a política de comunicação social; f) representar a Companhia perante o poder concedente e empresas afins; g) representar a Companhia perante outras empresas congêneres do setor de saneamento para o estabelecimento de políticas conjuntas; h) representar a Companhia em juízo e fora dele, ativa e passivamente; i) apresentar o relatório anual de administração da Companhia ao Conselho de Administração e à Assembleia Geral Ordinária; j) coordenar a elaboração do Plano Diretor de Saneamento da Companhia elaborado pelos diretores de Operações e de Investimentos, bem como acompanhar a aplicação das metas estabelecidas, promovendo sua constante atualização; k) propor metas, instrumentos normativos e decisórios que definam as políticas de planejamento do sistema de saneamento da Companhia; 1) coordenar, em conjunto com o Diretor de Operações, a contratação de empresa de serviços de saneamento básico, visando adquirir novas tecnologias operacionais para a Companhia; m) definir as diretrizes da política da Companhia referente a licitações e contratos para o fornecimento de bens, serviços e obras; n) nomear, em conjunto com o Diretor 
Administrativo, as comissões de licitação; o) prospectar e coordenar, em conjunto com o Diretor Financeiro, as atividades inerentes a projetos financiados por entidades e organismos internacionais; p) propor ao Conselho de Administração, em conjunto com o diretor da área interessada, e mediante parecer do Diretor Financeiro, a criação e a extinção de cargos na estrutura da Companhia (SANEPAR, 2012, p. 9-10).

lxxxi Disponível

http://www.sanepar.com.br/sanepar/calandrakbx/filesmng.nsf/ABF593B2D91E80298325729600465B3F/\$File/IAN200 2.pdf?OpenElement; acesso em 27/04/2017.

lxxxii Disponível em http://www.saneamentobasico.com.br/portal/index.php/arquivo/posicao-da-sanepar/; acesso em 06/11/2016

lxxxiii "Estudar os sistemas de ensino secundário e superior e as relações das escolas ou universidades com o Estado surge como ponto de partida indispensável a um estudo sociológico das elites. A socialização e a formação dos membros das futuras elites dependem estreitamente das instituições educativas (escolas de elite, privadas ou públicas, grandes liceus, grandes écoles, etc.) que favorecem a estruturação dos grupos, a constituição de redes e a aprendizagem de modos de gestão das relações e do exercício da autoridade” (SAINT-MARTIN, 2008, p. 52). 